\title{
Determination of Manufacturing Parameters for Maintaining Form Accuracy of Packaging Support Block Made with Polyurethane Foam
}

\author{
Jiwan KANG, Heeyoung MAENG*, Suin EUN
}

\begin{abstract}
A support block for packaging valuables usually uses a material with surface elasticity, such as polyurethane foam or polystyrene foam. This is to ensure that the surface can be well contacted and supported so that the contents of the package can be protected from vibration or shock when valuables are transported over long distances. In general, this polyurethane packaging support block is manufactured using an NC milling machine and a ball nosed end mill tool specially designed to cut the cushioned soft materials. However, because the elastic cushion of the material is very large, it is very difficult to implement the 3D form accuracy that can be in good contact with the surface of the packaged contents. This study tried to explore the manufacturing parameters that could maintain the good contact with the surface form of packaged valuables accurately and could support the contents stably, through the Taguchi technique, that minimizes the influence of uncontrollable factors through controllable factors. Using the characteristics value by Taguchi technique based on the experimental accumulated machining data under similar environment, the optimal manufacturing parameters such as the spindle speed, feedrate, step over, and tool path pattern were determined. And the manufacturing parameters determined through these analysis techniques have been verified practically by testing experiment using a group of expert's machining data. Also, in order to examine the suitability of these parameters, the prediction accuracy was confirmed by comparing it with a large amount of experimental data accumulated by experts. In addition, in order to confirm the packaging performance of the support block manufactured under these parameters, the vibration tests were performed on these samples to compare and analyze whether they satisfied the limits of the standard specification.
\end{abstract}

Keywords: Form accuracy; Manufacturing parameters; NC milling of polyurethane foam; Packaging suppot block; Taguchi technique; Vibration test

\section{INTRODUCTION}

With the recent development of the logistics industry and the exhibition fair event, it is increasingly necessary to safely transport valuables such as electronic products, expensive artworks, sculptures, jewelry, antiques, and cultural assets to long distances. When these valuables are safely transported, they usually go through a special packaging process, and most of them rely on the experience of experts. Companies specializing in this packaging industry use the cushioned and soft standardized packaging support block made of polyurethane or polystyrene block to effectively wrap the contents goods.

The support block used for this purpose should have adequate elasticity and protect the valuables from external impact as it is in contact with the content goods. To do this, the shape of the curved surface must have the consistent clearance so that the inner contact surface of the support block can smoothly contact the outer surface of the content goods [1]. The curved surface of support block is made into a suitable form by giving a uniformed margin considering the gap and pressing tolerance based on the contact region of the outer surface of the valuables, and then it is designed so that the surface of soft material foam is to be machined easily using $\mathrm{NC}$ (Numerical control) milling machine while satisfying the machining allowance [2].

At this time, deformation occurs in areas subject to excessive pressure due to poor form accuracy. If there is a gap with insufficient contact, external vibration cannot be blocked and damage such as scratches or cracks may occur on the content surfaces. When it is machined at NC milling machine, unlike when machining metal or hard materials, it uses a specialized ball nosed end mill tool having a needle protrusion on the cutter blade. Therefore, cushioned deformation on the surface of support block is inevitable.

Regarding this special machining cases, Kim et al. [3], as part of an effort to increase the surface roughness of the workpiece when $\mathrm{NC}$ milling of relatively light epoxy foam, the cutting conditions such as appropriate spindle rotation speed, axial depth of cut, are experimentally determined. Also, Min [4] and Zhang [5] calculated the amount of tool offset by considering the deformation of the contact surface between a specially manufactured tool and a workpiece when NC milling a soft polyurethane foam material.

In addition, Shim et al. [6] have studied a method for estimating the shock absorption rate of polyurethane foam through the speed at which the steel balls were dropped. Furthermore, Kim et al. [7] have suggested the dropping simulation of the outdoor unit of an air conditioner in a state of being packaged with polyurethane foam, and through these simulation data, they found the weakened regions and reinforced areas of the packaging support block.

However, there has been no research so far in which the manufacturing parameters have been decided to maintain form accuracy when machining the polyurethane foams, and no research has been conducted on the effect of interference and clearance gaps of the support block.

This study investigated the method of determining the manufacturing parameters that can maintain the form accuracy of the contact surface so that the support block can stably support the content goods. A new method using Taguchi technique $[8,9]$ is proposed to find the optimal manufacturing parameters, which is not only feed speed and spindle speed, but also many factors such as machining direction, axial depth of cutting, and spacing between paths, to act in a complex manner. And this method evaluated its applicability on the empirical data from a group of experts accumulated for a long time, and through a vibration test on the packaging support block in which manufacturing parameters were applied to the actual packaging process.

\section{MANUFACTURING PROCEDURE OF PACKAGING SUPPORT BLOCK}

The manufacturing process of packaging support block goes generally through the process as shown in Fig. 1. A 3D scanner is used to collect 3D scan data for the surface 
of the packaged object, and the shape of the support block form is designed based on the collected 3D data. At this time, after correcting the curved surface in consideration of gaps, elastic margins, and gouging, the tool path data for NC milling is generated for the curved surface of the contact part with the content goods.

Then, this NC data is input into the NC milling machine, and the milling work is performed on the table to complete the machining of the support block form. The next step is to assemble the various sub-elements that make up the packaging support block, and then place the contents inside the support block for packaging. This polyurethane foam has elasticity, but has stability in temperature change, chemical stability, shock and external vibration. Tab. 1 shows a comparison of three representative physical properties (i. e. conductivity, elastic modulus, and $\mathrm{pH}$ ) for the two materials of foam, such as polyurethane material and EVA (ethylen-vinyl acetate) foam.

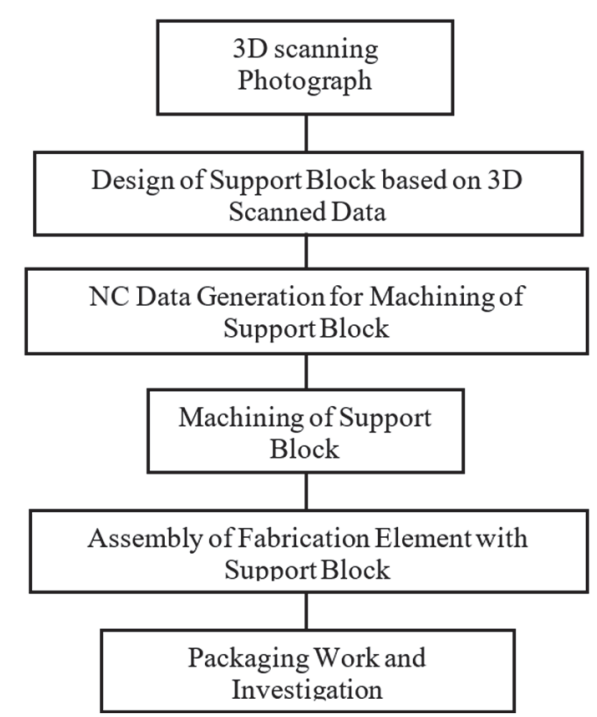

Figure 1 Process chart for manufacturing of packaging support block

Table 1 Properties of packaging support block materials

\begin{tabular}{|c|c|c|}
\hline Materials & Polyurethane foam & Eva foam \\
\hline Conductivity $/ \mathrm{W} \mathrm{m}^{-1} \mathrm{~K}^{-1}$ & 0.024 & 0.038 \\
\hline Elastic Modulus / MPa & 0.34 & 0.49 \\
\hline $\mathrm{pH}$ & 6.7 & 6.3 \\
\hline
\end{tabular}

\subsection{Collection of Shape Data Using 3D Scanning}

Although there are various scanning methods depending on the complexity of the shape to scan the surface of the package content goods, a spherical coordinate system 3D scanner is widely used as equipment for easy automatic scanning on a desktop. This is because it is good to measure all surfaces at once in one place without moving valuables as much as possible by adjusting the longitude and latitude angles of the spherical coordinate system.

Fig. 2 shows a typical spherical coordinate system 3D scanner. When data are collected using this spherical coordinate system, automatic scanning is performed using a macro after performing zero adjustment and calibration using a standard master ball. There is almost no loss time except for the time gap between scanner shooting and instrument setting, so high-speed scanning with high resolution is possible. After the scanning work is completed, the acquired data is automatically converted into the world coordinate system through the commercial application software.

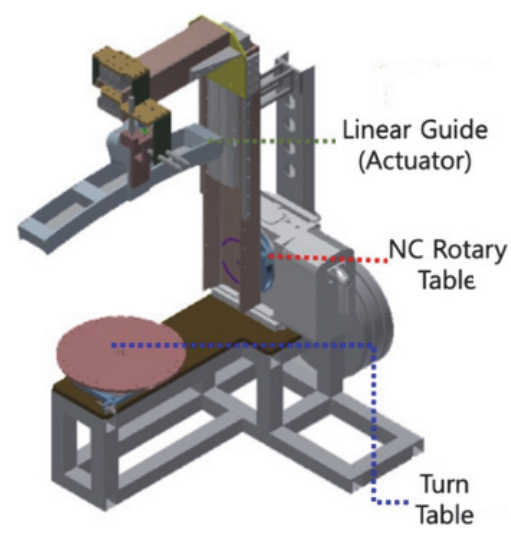

Spherical coordinate scanning

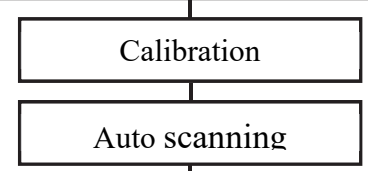

Alignment with transfomation Matrix

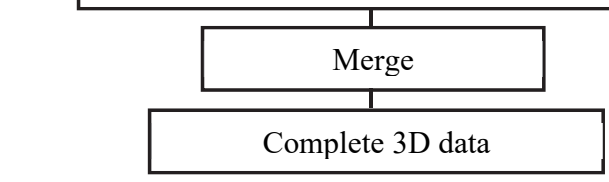

Figure 2 Spherical coordinate system device and 3D scanning process

\subsection{Design of Support Block Based on 3D Scanned Data}

Fig. 3 shows the scanned sample of a sculptured surface for content goods on a support block based on the scanned 3D data. At this time, the work of correcting the sculptured surface is performed in consideration of gaps, tolerances, and margins.

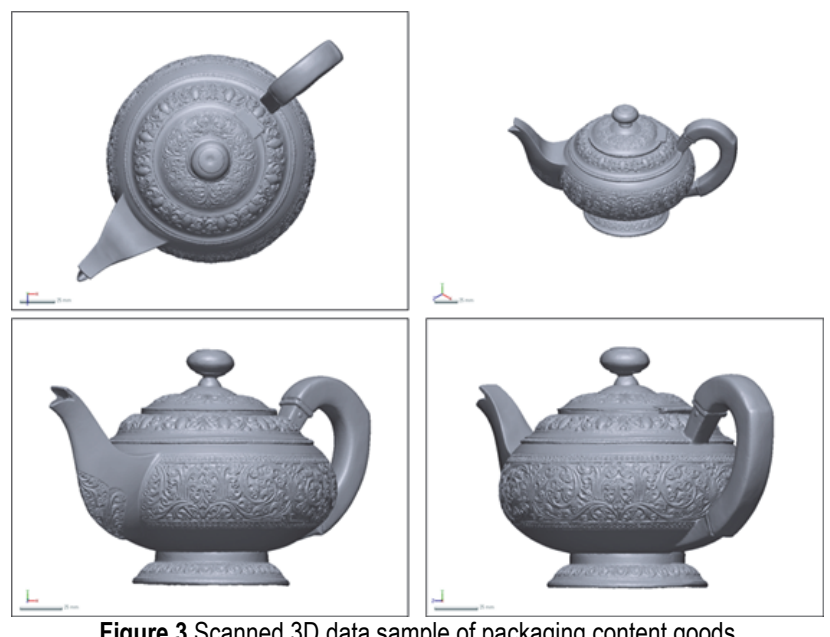

Figure 3 Scanned 3D data sample of packaging content goods

As the first step, as shown in Fig. 4a, the scan data of the packaged content goods is merged and placed at the world coordinate origin, and the size of the packaging support block is laid out in a rectangular shape as shown in Fig. 4b. 
And then, as shown in Fig. 4c, after placing them in a symmetrical structure at the center, it performed offsetting work considering gaps, tolerances, and margins to the normal direction of the curved surface. Finally, the cavity sculpture suface of the lower support block is completed by removing the protruded surface beyond the block boundary as shown in Fig. 4 d.

Also, the design process of upper support block is applied as the same design steps of lower support block. Then the whole design process is completed.

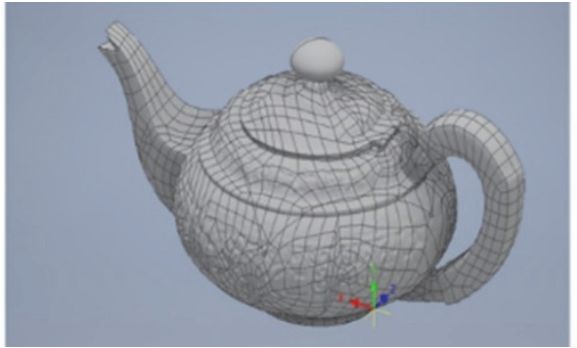

(a) Original scanned model

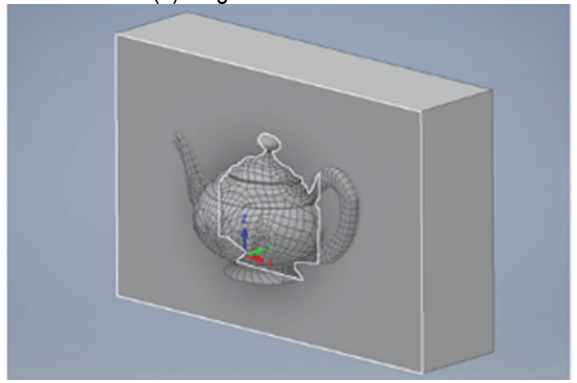

(b) Sizing of support frame block

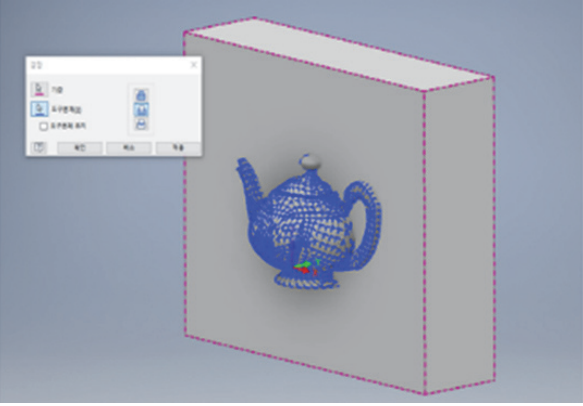

(c) Offsetting margin and clearance

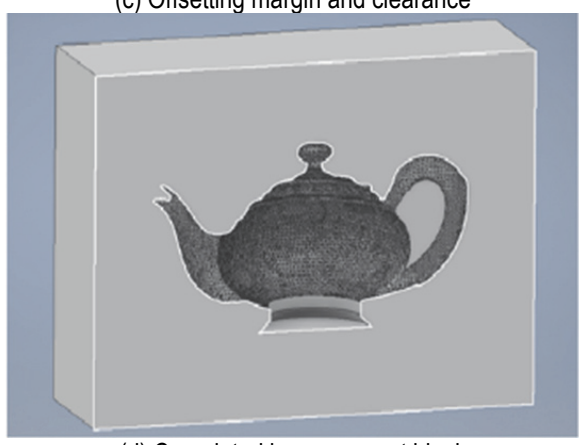

(d) Completed lower support block

Figure 4 Design process of support block based on 3D scan data

\subsection{Cutting Path Generation for Sculpture Surface}

The inner sculptured surface of support block goes through the process of calculating the cutting path for NC milling as shown in Fig. 5a, and the cutting tool used here is a special tool in the form of a ball end mill which has a needle-shaped protrusion as shown in Fig. 5b. This cutting path uses a lot of contour line cutting paths so that the slope condition varies smoothly and uniformly during the cutting process.

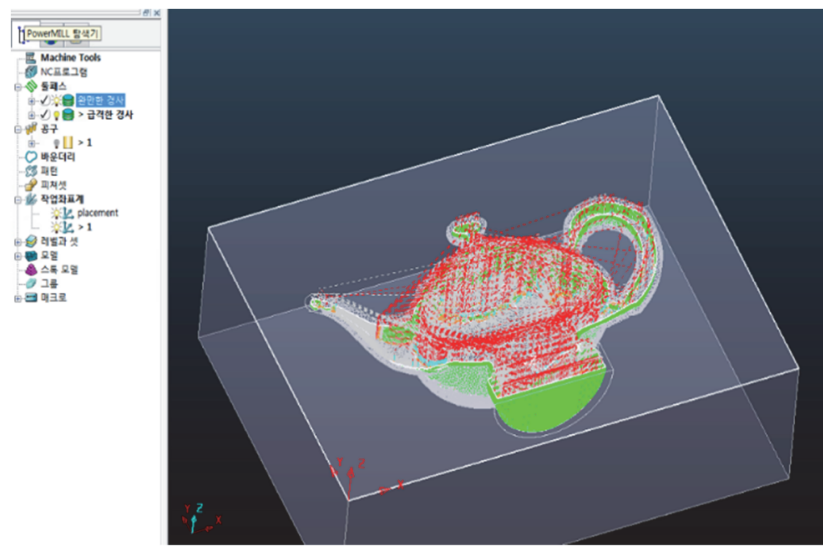

(a) Cutting path generation for inner surface

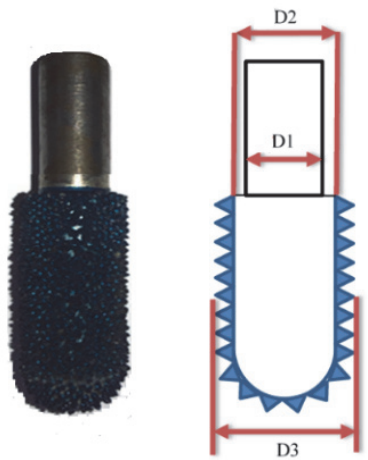

(b) cutting tool shape

Figure 5 Cutting path generation for inner suface and cutting tool shape

\subsection{Determination of Recommended Cutting Conditions}

When polyurethane foam of support block is cutting along the cutter path generated in sculptured surface, poor form accuracy is easy to appear unless appropriate cutting conditions are applied because there is a large amount of deformation of the workpiece due to the elastic cushion. The determination of appropriate cutting conditions is a complex problem in that many factors such as feed speed and spindle speed, as well as machining direction, tool axial cutting depth, and spacing between paths, must be simultaneously considered.

For this purpose, it is tried to search the recommended cutting conditions by considering the characteristics that have a major influence on the form accuracy, that is based on the cutting conditions that have been accumulated empirically through the expert group. To solve this problem, the Taguchi technique [8-11], which can easily evaluate the influence of each factor, was applied.

When the Taguchi technique is used, the influence of each factor of cutting conditions can be expressed in the form of a weight defined by the $\mathrm{S} / \mathrm{N}$ ratio. This technique attempts to find the optimum levels for the controllable variables or design parameters. It applies a simple analysis of means to model the results, which gives quantitative information on the control factor effects. The smaller the error value of the form accuracy, the higher the machining quality expressed and the smaller the better characteristics.

So, it would be possible to find out which condition is superior through the $\mathrm{S} / \mathrm{N}$ ratio response table obtained by substituting the results of multiple experiments ( $\mathrm{N}$ times) 
with form accuracy as a constraint as a local factor. In the $\mathrm{S} / \mathrm{N}$ ratio response table, a small value corresponds to the best factor level, so if a cutting condition corresponding to a small value is found in the response table, this becomes the optimal condition in the corresponding environmental experiment area.

Here, the form accuracy is expressed by defining the distance difference between the original 3D model data and the 3D model target data of the finished workpiece. The 3D data of the finished workpiece were collected using commercial T-Scanner [12], and the comparison of suface data between the original and finished one was performed using the $3 \mathrm{D}$ shape analysis program named Geomagic Control X [13]. The average of the distance difference between the surfaces was converted in this program.

\section{DETERMINATION OF OPTIMAL MANUFACTURING PARAMETERS}

\subsection{Experiment Setup for Searching Optimal Conditions}

The initial cutting conditions to search for the optimal cutting conditions are to select the factor that has the greatest influence on the form accuracy, and apply experimentally for two factors: the tool path pattern in the inclined direction and the step over. The Tinyrobo's TinyCNC-6060 milling machine was used in this experiment, as shown in Fig. 6, and a ball end mill for foam material manufactured by Taesan Solutions Co., Ltd. in Tab. 2 standard specification was used.

Table 2 Size specification of ball end mill used

\begin{tabular}{|c|c|c|c|}
\hline Shank diameter $D 1$ & $10 \mathrm{~mm}$ & Body diameter $D 2$ & $15 \mathrm{~mm}$ \\
\hline Blade Diameter $D 3$ & $16 \mathrm{~mm}$ & Blade accuracy & $50 \mu \mathrm{m}$ \\
\hline Blade length & $80 \mathrm{~mm}$ & Sank length & $50 \mathrm{~mm}$ \\
\hline Particle height & $0.5 \mathrm{~mm}$ & Particle width & $1.4 \mathrm{~mm}$ \\
\hline Size parameter & \multicolumn{3}{|c}{ *Refer to Fig. $5 \mathrm{~b}$} \\
\hline
\end{tabular}
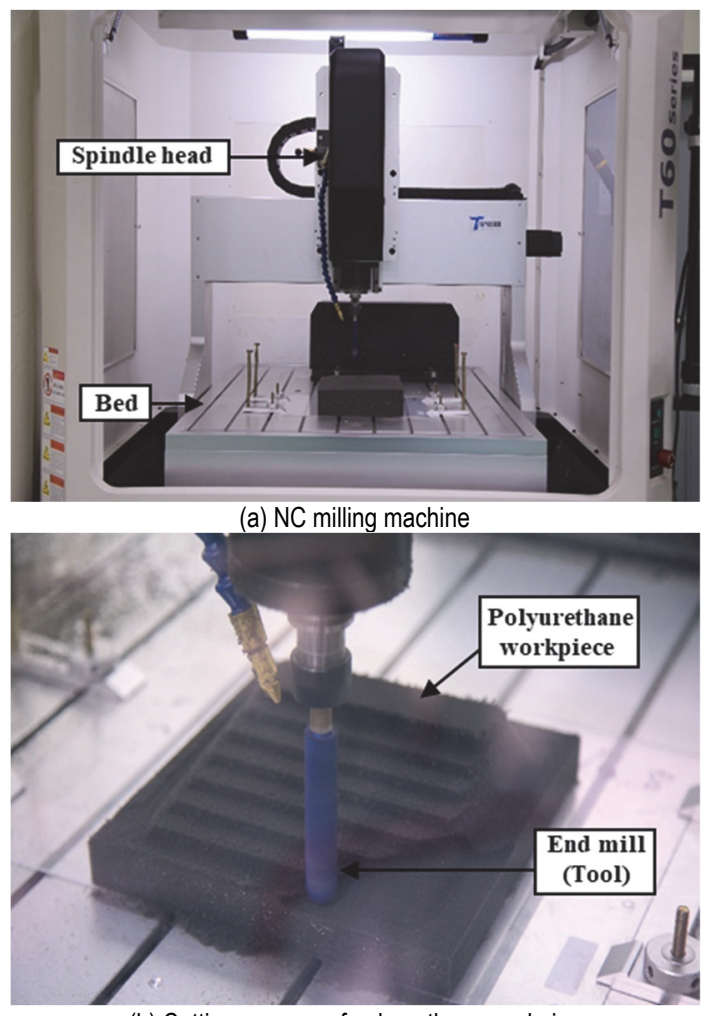

(b) Cutting process of polyurethane workpies

Figure 6 Configuration of NC milling machine and cutting process
The manufacturing model, as shown in Fig. 7, was performed on three parts of the inclined model: a gentle slope (inclination angle of $12^{\circ}$ ), a sudden slope (inclination angle of $60^{\circ}$ ), and a corner. The initial cutting conditions were three conditions as shown in Tab. 3, which are already empirically applied in actual on-site machining. And, as a means to examine the stability of the cutting state, it confirmed the surface roughness measurement using the Mitsutoyo SJ-400 instrument by selecting the same location for each of the gentle slope (inclination angle $12^{\circ}$ ), sudden slope (inclination angle $60^{\circ}$ ), and corner. Also, this measurement was applied to 9 samples that have been machined and set the cutoff value to $8 \mathrm{~mm}$.

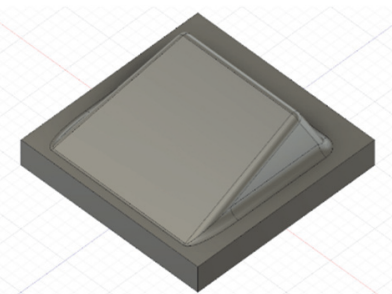

(a) Perspective view
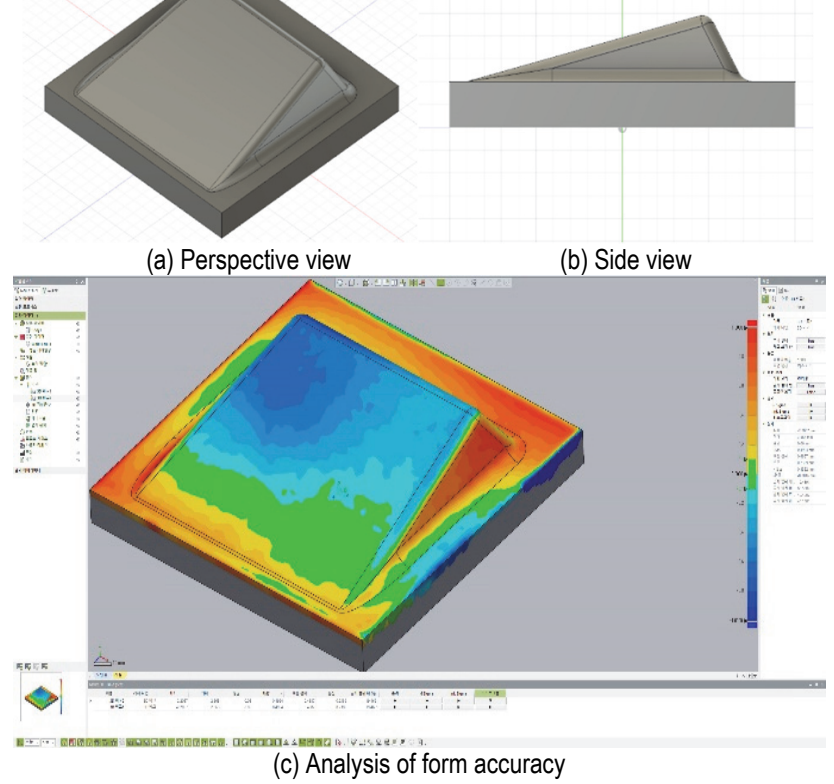

Figure 7 Surface model used for inclined machining

On the other hand, the measurement of 3D shape accuracy takes into account the concentricity evaluation of the finished product. As shown in Fig. 8, two shapes, spherical and cylindrical, were selected as target models. The three machining conditions were set in Tab. 3 in consideration of the steep slope in the spherical shape, and then the change value of the form accuracy according to the machining pattern was calculated as the $\mathrm{S} / \mathrm{N}$ ratio by the Taguchi technique.

The definition of $S / N$ ratio is different according to an objective function, that is, the characteristic value [15]. There are three kinds of characteristic valu : Normal is Best (NB), Lower is Better (LB) and Higher is Better (HB). Eq. (1) shows the formula for calculating the $S / N$ ratio for the LB characteristic. LB is preferred to determine the best control factor level in the $S / N$ ratio response table.

The $S / N$ ratio of LB can be calculated by

$S / N=-10 \log \left[\frac{1}{n} \sum_{i=0}^{n} y_{i}^{2}\right]$

where $n$ is the number of measurements, and $y_{i}$ the measured characteristic value.

Meanwhile, in the case of the spherical shape model, two types of machining are applied: a linear reciprocating pattern through raster machining, and a pattern machining 
the spherical surface with the ball end mill descending along the spiral slope through spiral machining. For these models, both shape precision and concentricity were measured and compared.

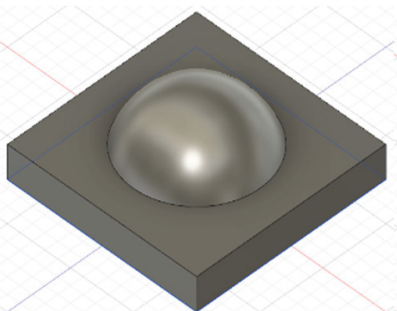

(a) Spherical surface model Figure 8 Two kinds of 3D model used for machining verification

Table 3 Three kinds of initial machining condition setting

\begin{tabular}{|c|c|c|c|c|}
\hline \multirow{2}{*}{$\begin{array}{c}\text { Conditions } \\
\text { factor }\end{array}$} & \multirow{2}{*}{ unit } & \multicolumn{3}{|c|}{ Comparison conditions } \\
\cline { 3 - 5 } & & I & II & III \\
\hline Spindle speed & $\mathrm{rpm}$ & 1,800 & 2,000 & 2,200 \\
\hline Feedrate & $\mathrm{mm} / \mathrm{min}$ & 1,000 & 1,250 & 1,500 \\
\hline Step over & $\mathrm{mm}$ & 0.5 & 0.6 & 0.7 \\
\hline pattern & direction & $X$-axis & $Y$-axis & Diagonal \\
\hline
\end{tabular}

Tab. 4 shows the results of form accuracy measured for each experimental condition and Tab. 5 is the evaluated result of Taguchi characteristic coefficient ( $S / N$ value) obtained by applying the cutting conditions of Tab. 3 to the form accuracy distribution of Tab. 4. According to these results, the $S / N$ ratio shows a large difference of up to $280 \%$.

For the object to be machined in Fig. 7, the trends of the $S / N$ ratio obtained through Eq. (1) are shown in Fig. 9 to Fig. 11.

As a result, from the point of view of form accuracy, the average value at experiment No. 9 was good at the gentle slope, the value of No. 3 was better at the sudden slope, and the value of No. 4 was best at the corner.

Table 4 Results of form accuracy for each codition (absolute value, $\mathrm{mm}$ )

\begin{tabular}{|c|c|c|c|}
\hline Sample number & gentle slope & sudden slope & corner \\
\hline 1 & 0.2645 & 0.0895 & 0.2989 \\
\hline 2 & 0.1175 & 0.0660 & 0.2770 \\
\hline 3 & 0.1002 & 0.0148 & 0.3047 \\
\hline 4 & 0.0660 & 0.0390 & 0.1175 \\
\hline 5 & 0.1651 & 0.1475 & 0.3039 \\
\hline 6 & 0.0670 & 0.0347 & 0.2390 \\
\hline 7 & 0.2074 & 0.1779 & 0.4977 \\
\hline 8 & 0.2426 & 0.6510 & 0.4725 \\
\hline 9 & 0.0420 & 0.1315 & 0.9999 \\
\hline
\end{tabular}

Table 5 Evaluated result of Daguchi Coefficient (Calculated S/N ratio)

\begin{tabular}{|c|c|c|c|c|c|c|}
\hline \multirow{3}{*}{ S/NRatio } & \multicolumn{3}{|c|}{$\begin{array}{c}\text { Spindle speed } \\
\text { (Lv. 1/2/3) }\end{array}$} & \multicolumn{3}{c|}{$\begin{array}{c}\text { Feedrate } \\
\text { (Lv. 1/2/3) }\end{array}$} \\
\cline { 2 - 7 } & \multicolumn{3}{|c|}{ Step Over (Lv. 1/2/3) } & \multicolumn{3}{c|}{ Pattern (Lv. 1/2/3) } \\
\hline \multirow{2}{*}{ GentleSlope } & 15.0 & 19.2 & 14.7 & 14.1 & 14.8 & 22.7 \\
\cline { 2 - 7 } & 13.5 & 21.8 & 15.7 & 14.8 & 16.9 & 16.1 \\
\hline \multirow{2}{*}{ Suddenslope } & 23.8 & 22.1 & 8.0 & 18.6 & 8.2 & 22.0 \\
\cline { 2 - 7 } & 8.4 & 21.1 & 17.5 & 18.0 & 19.1 & 8.5 \\
\hline \multirow{2}{*}{ Corner } & 10.6 & 12.6 & 3.1 & 9.3 & 8.8 & 4.1 \\
\cline { 2 - 7 } & 9.1 & 4.4 & 8.4 & 4.4 & 9.0 & 9.6 \\
\hline
\end{tabular}

\subsection{Estimated Result of Optimal Cutting Conditions}

When examining the optimal cutting conditions based on the case where the mesh characteristic value is small, in

the results of Tab. 5, first, for the case of the gentle slope machining, the spindle speed which is the condition III $(2,200 \mathrm{rpm})$ in Tab. 3 , is suitable. It can be seen that condition I $(0.5 \mathrm{~mm})$ is most suitable for the amount of stepover, condition I $(1,000 \mathrm{~mm} / \mathrm{min})$ for the feed speed, and condition I ( $X$-axis direction) for the pattern.

On the other hand, looking at the relative influence of each machining condition here, in the case of spindle speed and pattern, there is not much difference between each condition, but the difference between the maximum and minimum values in the feed rate and stepover is large.

In the case of sudden inclined part machining, the difference between the maximum and minimum values appears large in most cases. Condition III $(2,200 \mathrm{rpm})$ is suitable for spindle speed, but condition I $(0.5 \mathrm{~mm})$ is the most suitable for the amount of stepover, and feed speed. Therefore, when viewed as a whole, the condition II $(1,250$ $\mathrm{mm} / \mathrm{min}$ ) and the condition III (diagonal direction) are appropriate conditions.

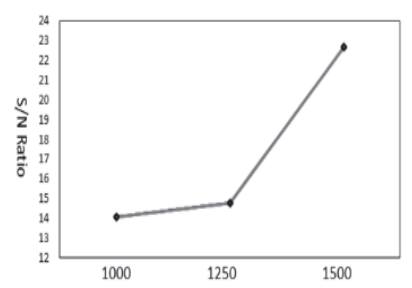

(a) Feed Speed(mm/min)

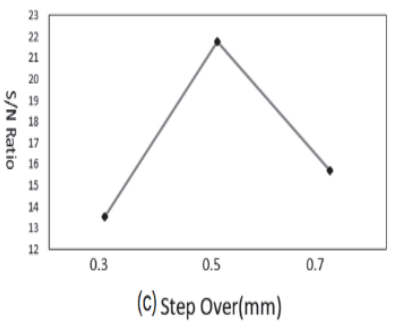

Figure 9 Main effects $\mathrm{S} / \mathrm{N}$ ratio of a gentle slope

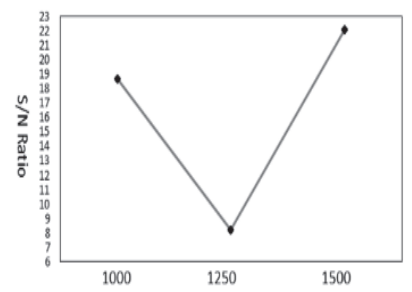

(a) Feed Speed $(\mathrm{mm} / \mathrm{min})$
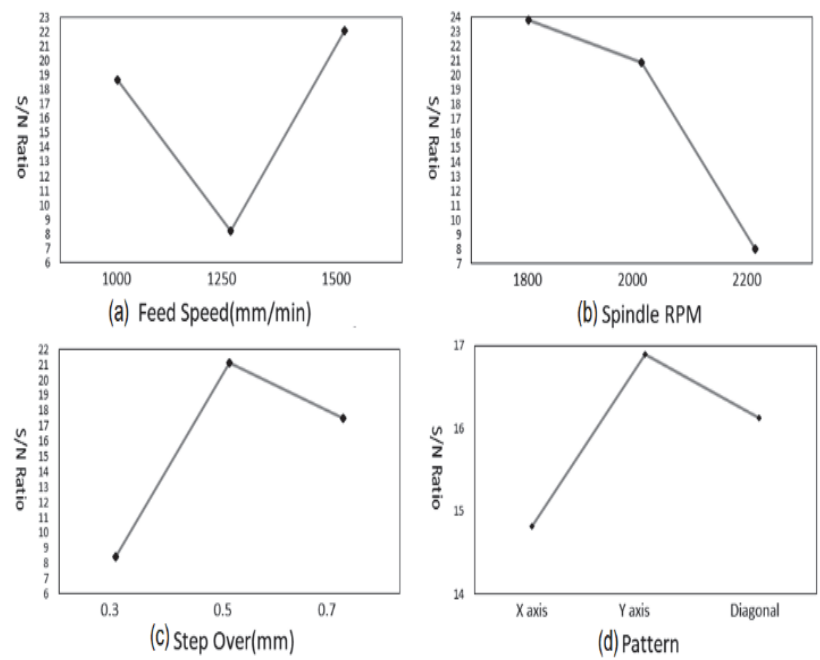

(b) Spindle RPM

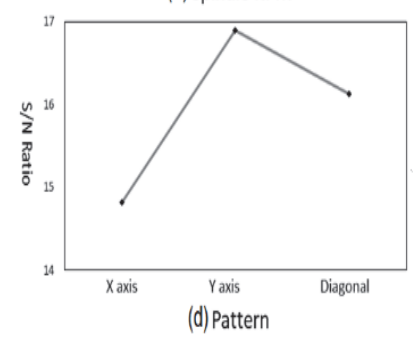

Figure 10 Main effects $\mathrm{S} / \mathrm{N}$ ratio of a sudden slope

In addition, the difference between the maximum and minimum values is generally large in the case of corner machining. Condition III $(2,200 \mathrm{rpm})$ is suitable for the spindle speed, but condition II $(0.6 \mathrm{~mm})$ is the most suitable for the stepover. Also, it can be seen that condition 
III $(1,500 \mathrm{~mm} / \mathrm{min})$ for the feed speed and condition I $(X$ axis direction) for the pattern are appropriate.

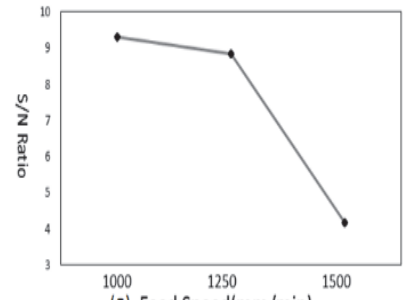

(a) Feed Speed(mm/min)

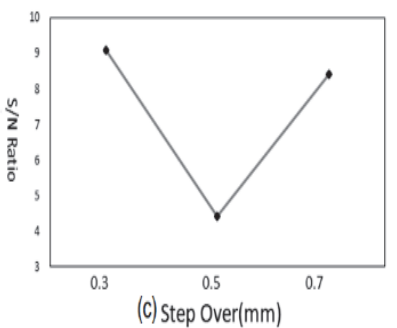

Figure 11 Main effects $\mathrm{S} / \mathrm{N}$ ratio of a corner

In view of these results, when cutting regardless of the type of sculptured surface, that is considered as a case of cutting a sculptured surface including all shape elements such as a gentle slope, a sudden slope, and a corner, it is recommended to set the cutting conditions by considering the overall distribution of $S / N$ values.

Table 6 The resulted optimal cutting condition

\begin{tabular}{|c|c|c|c|}
\hline & gentle slope & sharp slope & corner \\
\hline Spindle / RPM & 2000 & 1800 & 2000 \\
\hline Feed speed / mm/min & 1500 & 1250 & 1000 \\
\hline Step over / mm & 0.5 & 0.5 & 0.3 \\
\hline Pattern & $Y$-axis & $Y$-axis & Diagonal \\
\hline
\end{tabular}

Hence, in the environmental conditions targeted in this experiment, the spindle speed is set to No. III $(2,200 \mathrm{rpm})$, the feed speed is set to No. II $(1,250 \mathrm{~mm} / \mathrm{min})$, and the stepover is set to No. I $(0.5 \mathrm{~mm})$. And it can be determined that the pattern III condition (diagonal direction) is an appropriate condition.

\subsection{Measurement Results of Form Accuracy}

In order to verify the cutting characteristics of the cutting pattern according to the shape of the workpiece against the previously recommended cutting conditions, the form accuracy was examined for two models having spherical and cylindrical surfaces as shown in Fig. 8.

For the cylindrical surface model, the $X$-direction cutting pattern and the $Y$-direction cutting pattern were applied, and for the spherical model, the cutting patterns in the linear cutting direction and the spiral-linear direction were applied. At this time, the form accuracy of the machined product was measured with a 3D scanner and compared with the CAD prototype model of Fig. 8.

Table 7 Comparison of concentricity error for each model

\begin{tabular}{|c|c|c|c|}
\hline Spherical & $\begin{array}{c}\text { ConcentricityError } \\
/ \mathrm{mm}\end{array}$ & CylindricalModel & $\begin{array}{c}\text { Concentricityerror } \\
/ \mathrm{mm}\end{array}$ \\
\hline $\begin{array}{c}\text { Straight } \\
\text { direction }\end{array}$ & 0.2639 & $X$-axis direction & 0.5039 \\
\hline $\begin{array}{c}\text { Spiral } \\
\text { direction }\end{array}$ & 0.1749 & $Y$-axis direction & 0.3925 \\
\hline
\end{tabular}

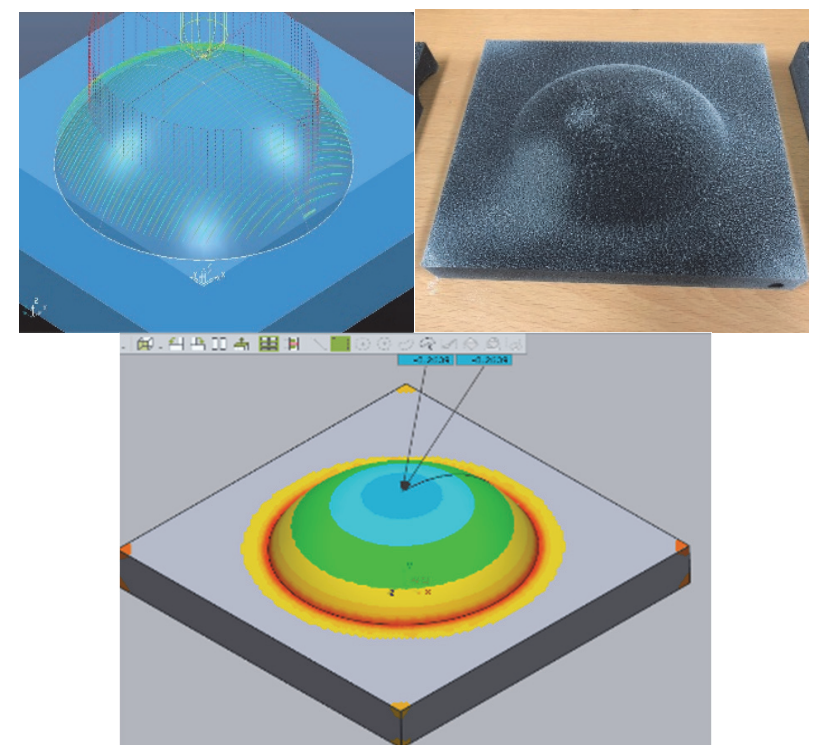

(a) Form accuracy for straight path

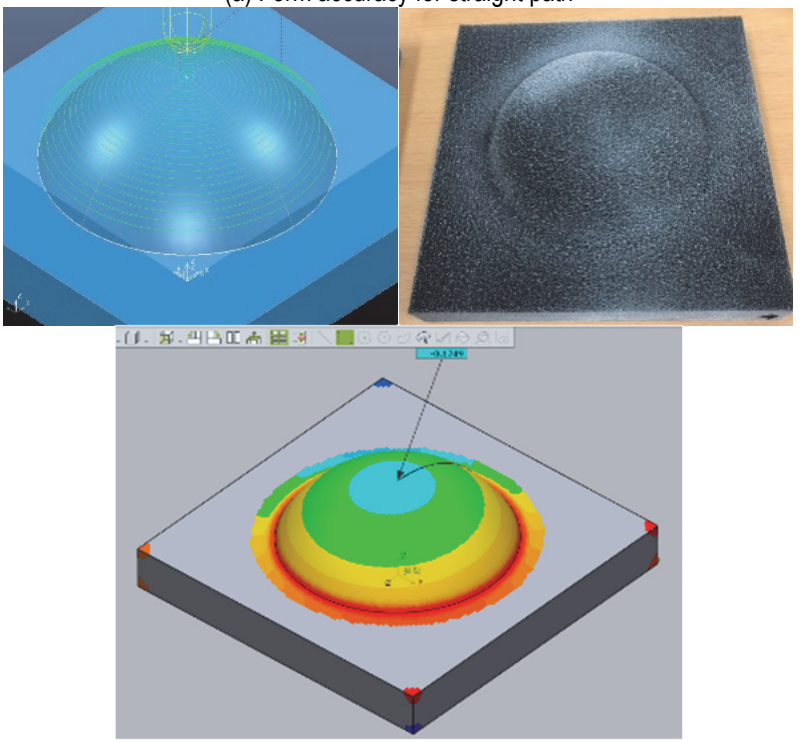

(b) Form accuracy for spiral path

Figure 12 Form accuracy for straight and spiral path applied to spherical model

The error distribution diagram is shown in Fig. 12 to Fig. 13, in the form of a distribution map according to the chromaticity applied to the surface.

As a result, it can be seen that the shape error (the amount of deformation of the workpiece) is largely generated in a portion or a corner portion having a sudden inclination. Also, by inputting these scanned data into the Geomagic Control X program [13, 14], the center coordinate eccentricity of the regression analysis surface between the original CAD model and the measured cloud data was obtained, and this was calculated as the concentricity of the spherical surface and the cylinder. The results are shown in Tab. 7.

Here, the concentricity can be viewed as a scattering of the shape accuracy error for the processed sculptured surface. When evaluating the form accuracy according to the cutting pattern, the error is the largest at $0.5039 \mathrm{~mm}$ when the cylindrical surface is processed in the $\mathrm{X}$ direction.

When the spherical surface was processed in the vortex-linear direction, it was found to be the smallest as $0.1749 \mathrm{~mm}$, indicating that the shape accuracy when machining the spherical surface in the vortex-linear direction was the best. 

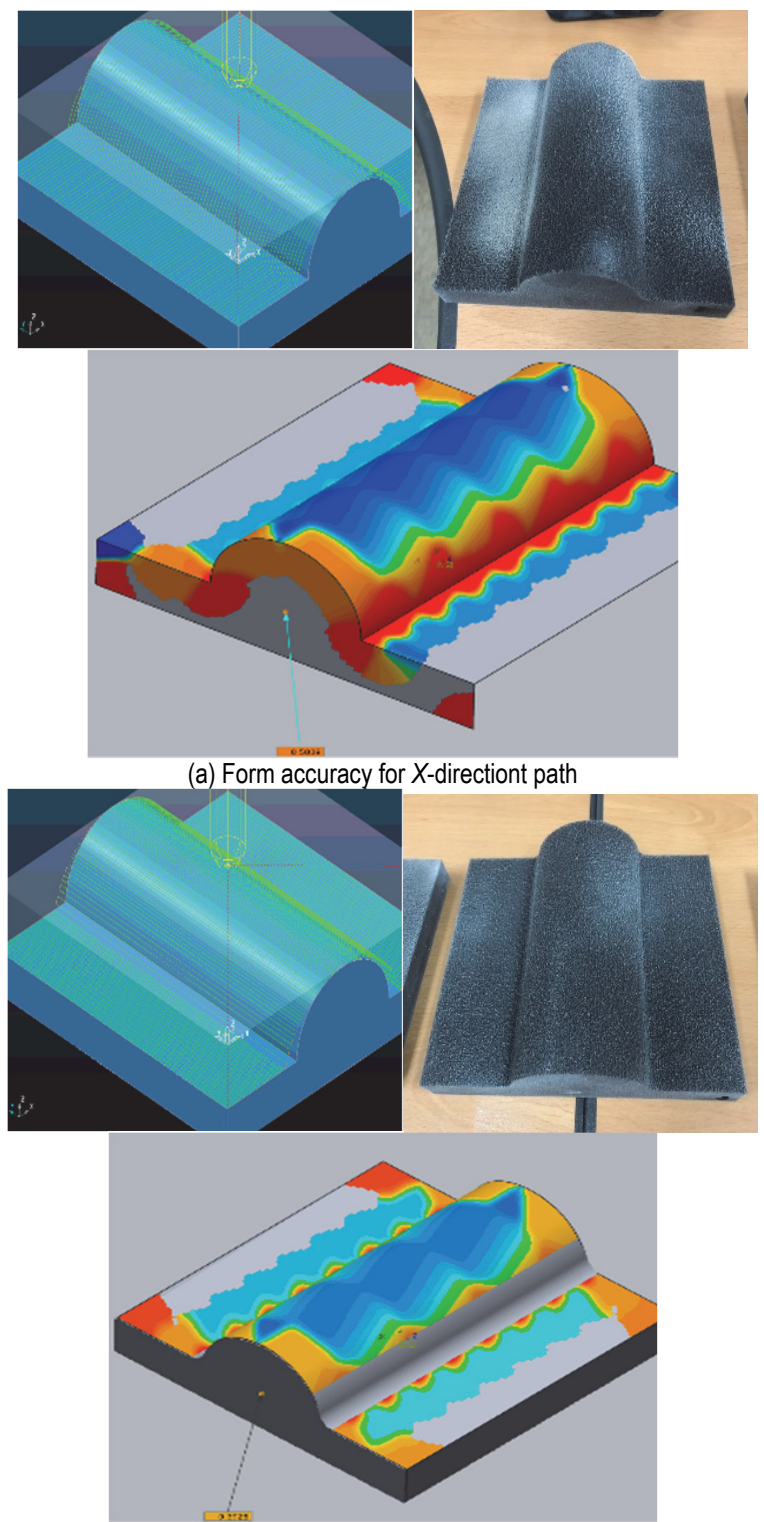

(b) Form accuracy for $Y$-direction path

Figure 13 Form accuracy for $X$ and $Y$-direction path applied to cylindrical model

In addition, when comparing only the machining of the spherical and cylindrical surfaces regardless of the cutting pattern, it shows that the form accuracy when machining the spherical surface is superior to that of machining the cylindrical surface, which is the slope of the cutting path or the amount of step-over due to the nature of the workpiece. It can be said that the smaller the change, the better the form accuracy is.

\subsection{Review of Packaging Performance by Vibration Test}

In order to examine the packaging performance according to the clearance of the packaging surface, an experiment was conducted on packaged products and boxes. This experiment was conducted for four packaging methods: PU (polyurethane) packaging with small gap which is machined by recommended machining conditions in this study, PU foam packaging with large gap which is machined by conventional cutting conditions, cotton felt packaging using a goft cotton fiber cloth, and bubble wrap packaging using vinyl with bubble for general shock mitigation.
The process of machining of support block and packaging for this experiment is as shown in Fig. 14a to Fig. 14d. Fig. 14a is the process of cutting the PU material on the NC milling machine, and Fig. 14b is the process of inserting the content goods into the support block. Fig. 14c is the process of putting the support block into the packaging box, and Fig. 14d shows the process of mounting it on the vibrator for the vibration test.

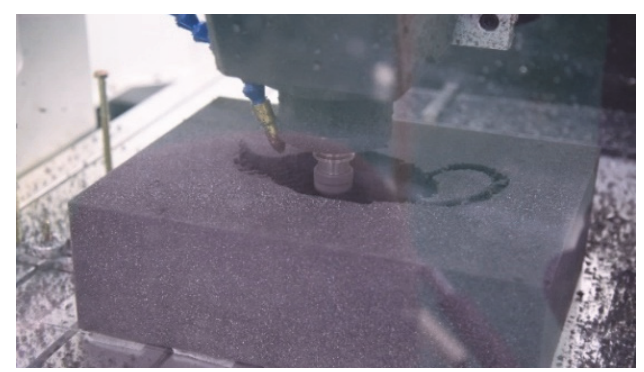

(a) Machining the sculpture surface on the PU support block

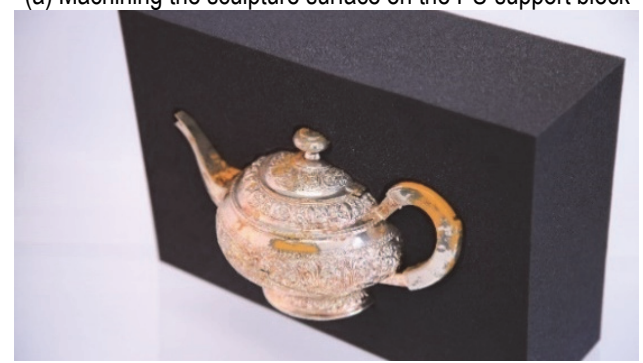

(b) Placement of the contents on the support block
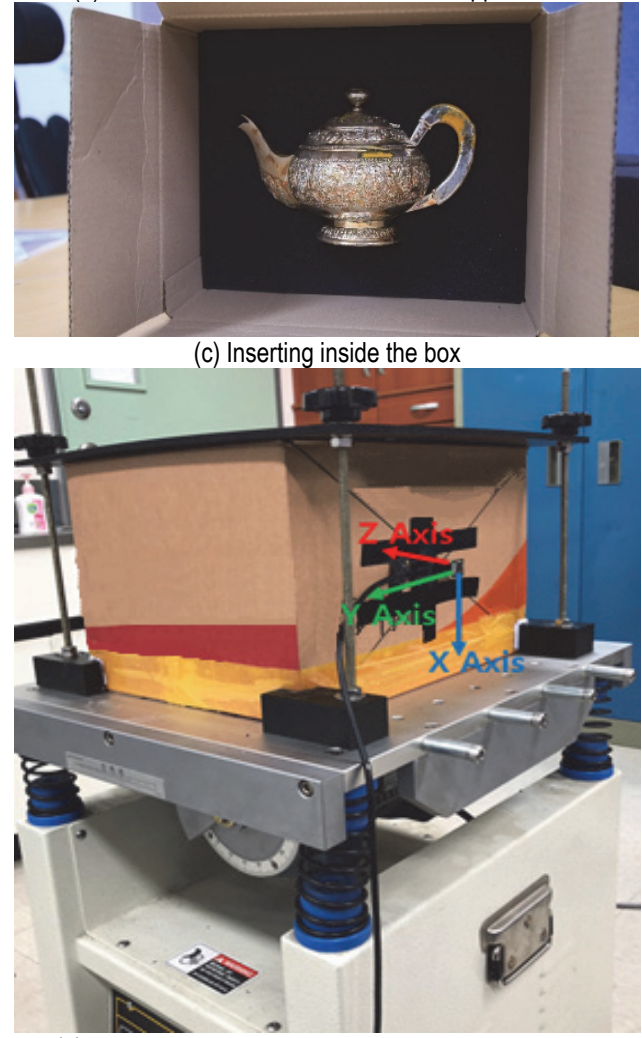

(d) Mounting the packaging box on the vibration tester

Figure 14 Arrangement for the vibration shock experiment

The vibration test standards related to the frequency band affecting the packaging should follow the vibration test method of KS A ISO 1017. The frequency was linearly increased from $10 \mathrm{~Hz}$ to $40 \mathrm{~Hz}$ for 15 minutes.

In order to know the vibration displacement input from the excitation tester according to each packaging method, 
an accelerometer is attached to the side of the packaging box to achieve $10 \mathrm{~Hz}$ and $20 \mathrm{~Hz}$. The input amplitude was measured at $30 \mathrm{~Hz}$ and $40 \mathrm{~Hz}$ and compared with the amplitude of the package contents.

In this vibration test, vibration is given under the same conditions for each packaging method, and the RMS (root mean square) acceleration value as for each $1 \mathrm{~Hz}$ section is obtained through the response acceleration according to the time as shown in Eq. (2), and the vibration level $d B(V)$ is calculated using Eq. (3).

$a_{r m s}=\sqrt{\frac{1}{T} \int_{t_{i}}^{t_{i+1}} a(t)^{2} \mathrm{~d} t}$

$\mathrm{dB}(\mathrm{V})=20 \log \frac{a_{r m s}}{10^{-6}}$

where $a$ is the acceleration response, $T$ is time taken to increase by $1 \mathrm{~Hz}$, and $\mathrm{T}=t_{i+1}-t_{i}$.

The estimated RMS acceleration value and vibration level was compared for each method. At this time, the acceleration sensor was attached so that the $X$-axis direction was the direction of gravity.

Tab. 8 is the data comparing the amplitude of the input from the vibration tester for each frequency and the amplitude of the package contents. In Fig. 15, the ratio of the amplitude of the packaged contents to the amplitude input from the vibration tester is compared and graphed for comparison. The smaller the value, the greater the decrease in the input amplitude.

Table 8 Amplitude of frequency interval by packaging method (Unit : mm)

\begin{tabular}{|c|c|c|c|c|c|}
\hline \multicolumn{2}{|c|}{} & $10 \mathrm{~Hz}$ & $20 \mathrm{~Hz}$ & $30 \mathrm{~Hz}$ & $40 \mathrm{~Hz}$ \\
\hline \multirow{2}{*}{$\begin{array}{c}\text { PU package with } \\
\text { small gap }\end{array}$} & content & 1.171 & 0.179 & 0.171 & 0.196 \\
\cline { 2 - 6 } & box & 1.348 & 1.134 & 1.141 & 1.205 \\
\hline \multirow{2}{*}{$\begin{array}{c}\text { PU package with } \\
\text { large gap }\end{array}$} & content & 2.102 & 1.287 & 0.63 & 0.678 \\
\cline { 2 - 6 } & box & 1.348 & 1.134 & 1.142 & 1.205 \\
\hline \multirow{2}{*}{ Cotton felt } & content & 0.975 & 1.275 & 2.125 & 1.697 \\
\cline { 2 - 6 } & box & 1.355 & 1.142 & 1.149 & 1.207 \\
\hline \multirow{2}{*}{ Bubble wrap } & content & 2.359 & 1.232 & 0.678 & 0.272 \\
\cline { 2 - 6 } & box & 1.131 & 1.135 & 1.147 & 1.206 \\
\hline
\end{tabular}

The PU packaging support block with small gap, which is machined by recommended manufacturing conditions of this study, shows very stable support performance in all frequency ranges compared to other packaging methods.

Fig. 15 shows the acceleration response according to each packaging method, and Fig. 16 shows the vibration level for each packaging method in a table for comparison.

In the case of PU packaging with large gap and the cotton felt packaging, it was confirmed that the packaged product was not properly supported over the entire frequency range and showed a large range of vibration levels.

In the case of packaging using bubble wrap, it has a large amplitude range in the range of $10 \mathrm{~Hz}$ to $20 \mathrm{~Hz}$. Also, the vibration is stabilized thereafter, so it can be confirmed that the vibration level temporarily rises around the $30 \mathrm{~Hz}$ section. Therefore, it was found that the PU pavement with small gap showed a better amplitude reduction rate than other packaging methods after $20 \mathrm{~Hz}$.

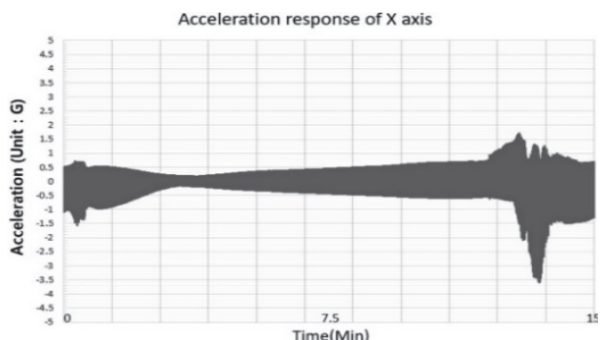

(a) PU packing with small gap

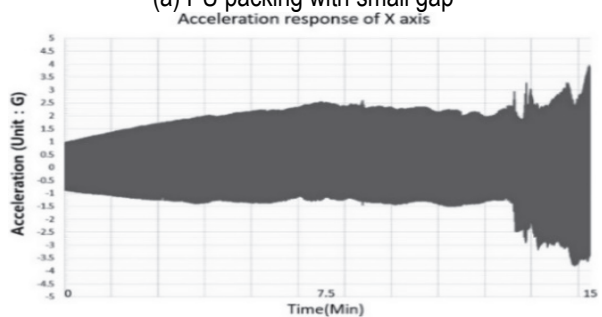

(b) PU packing with large gap

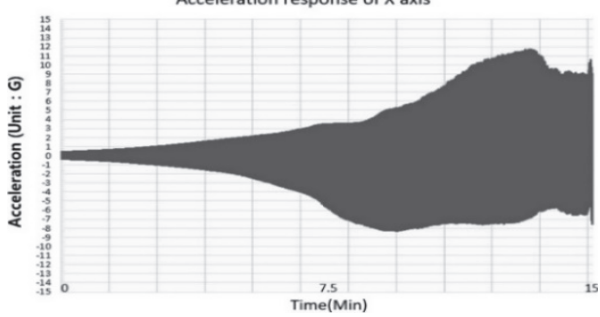

(c) Cotton felt

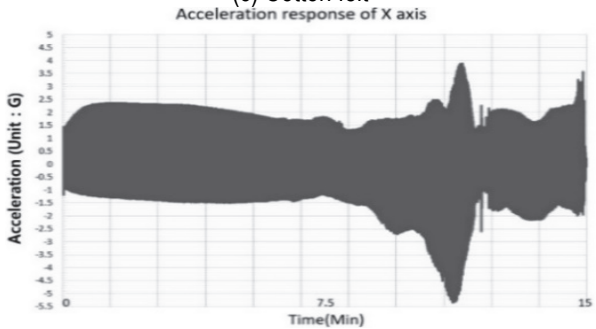

(d) Bubble wrap

Figure 15 Acceleration response of each packing method

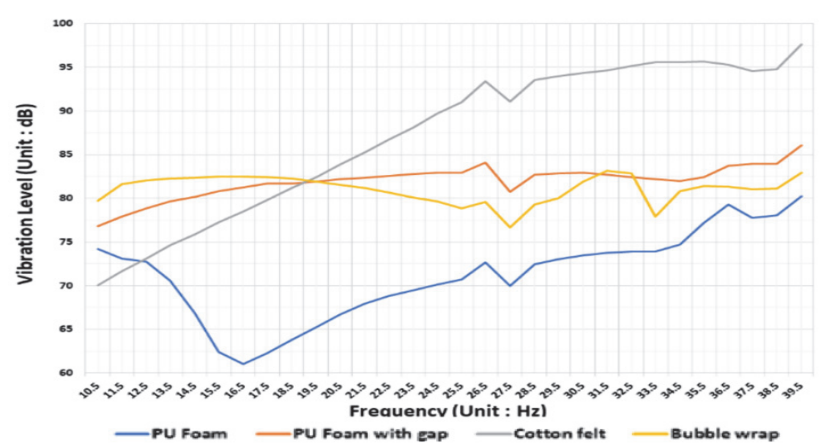

Figure 16 Vibration level of each packing supports method

\section{CONCLUSION}

Because the polyurethane materials used for packaging support block of valuables have high cushion and elasticity, it is not easy to manufacture them while maintaining form accuracy, which is an important factor that allows the contents to be well protected from shock or vibration during the transfer process. For this reason, it is also very important to determine well the various manufacturing parameters in the machining of packaging support block.

This study explored the manufacturing conditions that can maintain the form accuracy of the contact surface so that the support block can stably support the contents. 
These parameters, not only feed speed and spindle speed, but also many factors such as machining direction, tool axial cutting depth, and spacing between paths, are considered in a complex manner.Based on the manufacturing data accumulated by a group of field experts for a long time, the search process of the optimal condition using the Taguchi's method was applied. The optimal conditions were searched through these analysis results, considering the characteristics values that affect the form accuracy as the initial conditions, and considering the mesh characteristic values of the Taguchi technique derived from main effect $\mathrm{S} / \mathrm{N}$ ratio for a gentle slope, sudden slope, and a corner. As a result, it was found to be optimal that the appropriate feed rate is $1,250 \mathrm{~mm} / \mathrm{min}$, the spindle speed is $2,200 \mathrm{rpm}$, and the stepover is $0.5 \mathrm{~mm}$ in the case of cutting a sculptured surface that includes all of a gentle slope, a sudden slope, and a corner. Also, it could be revealed that it is excellent to select the diagonal direction for the cutting patterns, and the PU packing with small gap, which is machined by recommended manufacturing conditions of this study, showed very stable support performance in all frequency ranges compared to other packaging methods in the experiment of vibrational shock test.

However, since these optimal conditions were limited to the environment and to the machinability of the ball end mill used in this study, these conditions may change a lot if the machinability of these tools is different. For this case, if this algorithm is supplemented with the wide range of experience data when a ball end mill of a different shape is applied, it could be used as it is expected that the conditions in the corresponding environment can be expanded to general manufacturing purpose.

For the follow-up study, it is suggested that a lot of empirical data on a wider range of conditions and environments should be accumulated and applied. If a lot of comprehensive cutting data is accumulated for various support block materials with different hardness and elastic modulus, it is thought that it will be possible to derive optimized conditions in the applicable environment by applying the methodology in this study. In addition to the Taguchi method in which such a large amount of data is secured, it is considered possible to use big data-based selflearning artificial intelligence techniques.

\section{Acknowledgements}

This research was conducted with the support of research funding for general projects in the Seoul National University of Science and Technology.

\section{REFERENCES}

[1] Hyun, M. J. \& SuIl, K. (2015). Random Vibration Characteristics of Fruits in Packaging System for Parcel Delivery Service. Korean jounal of packaging science \& technology, 21(2), 67-71. https://doi.org/10.20909/kopast.2015.21.2.67

[2] Kim, J. G., Kim, J. Y., \& Kim, H. S. (2019). Design for Improving Impact Resistance of Microwave Oven Using Drop-Impact Analysis. Journal of the Korean society for power system engineering, 13(3), 53-58.

[3] Nam-Hun, K. (2012). Selection of the Optimal Machining Condition for a High-hardness Resin using the 5-axis Machine. Journal of the Korean Society of Manufacturing Process Engineers, 11(5), 29-34.
[4] Se-Hong, M. \& Hui-Song, K. (2000). A Study of an Effect of Tool Offset on Cutting Precision Considering Cutting Force in Polyurethane Foam Cutting. The Korean Society of Mechanical Engineers, 24(12), 3018-3025.

[5] Zhang, Y. \& Wu, Z. (2007). Offset Face Gear Drives: Tooth Geometry and Contact Analysis. Journal of Mechanical Design, 119(1), 114-119. https://doi.org/10.1115/1.2828772

[6] Shim,V. P. W., Tu, Z. H., \& Lim, C. T. (2000). Two-dimensional response of crushable polyurethane foam to low velocity impact. International Journal of Impact Engineering., 24(6), 703-731. https://doi.org/10.1016/S0734-743X(99)00149-9

[7] Hyung-Seok, K., Boo-Yoon, L., \& Sanghoon, L. (2018). Drop Impact Analysis of Outside Cooling Unit Package of System AirConditioner and Experimental Verification. Journal of the Korea Academia-industrial Cooperation Society, 19(4), 111-116.

[8] Tae, H. K., Chang, H. S., \& Rac, G. L. (2013). Optimization of Design Parameters for Lock-Claws of Pneumatic Fitting Using Taguchi Method. Transactions of the Korean Society of Mechanical Engineers, 37(12), 1541-1546. https://doi.org/10.3795/KSME-A.2013.37.12.1541

[9] Jun, W. L., Jian, J., Tae, J. K., \& Dae, K. B. (2013). Study of Optimal Machining Conditions of Ultrasonic Machining By Taguchi's Method. Transactions of the Korean Society of Mechanical Engineers-A, 37(2), 213-218. https://doi.org/10.3795/KSME-A.2013.37.2.213

[10] Crnjac, M., Aljinovic, A., Gjeldum, N., \& Mladineo, M. (2019). Two-stage product design selection by using PROMETHEE and Taguchi method: A case study. Advances in Production Engineering \& Management, 14(1), 39-50. https://doi.org/10.14743/apem2019.1.310

[11] Sterpin Valic, G., Cukor, G., Jurkovic, Z., \& Brezocnik, M. (2019). Multi-Criteria Optimization of Turning of Martensitic Stainless Steel for Sustainability. Int. Journal of Simulation Modelling, 18(4), 632-642. https://doi.org/10.2507/IJSIMM18(4)495

[12] T-Scan Manual, TaeSan Solution Ltd., (2016), 1-75.

[13] Hee, Y. M. (2014). Development of automation devices for the 3D digital measuring and preservation of archival artifacts, Annual Research Report, National Archives. Ministry of Security and Public Administration, 1-286.

[14] Suin, E. (2019). A Study on the Machining Condition of 3D Shape Polyurethane Packaging Support. Master's thesis, Seoul National Univ. of Science \& Technology.

[15] William, Y, F. \& Clyde, M. C. (1995). Engineering Methods for Robust Product Design : Using Taguchi Methods in Technology and Product Development. Addison Wesley Publishing Company, Reading, Massachusetts, 54-59.

[16] Suin, E., Jiwan, K., \& Heeyoung, M. (2021). A Study on the Optimum Machining Conditions of Polyurethane Materials used for Valuable Packaging Blocks. International Journal of $u$ - and e-Service, Science and Technology, 14(2).

\section{Contact information:}

Ji-wan KANG, Doctorial Graduate Student

Seoul National University of Science and Technology,

232, Gongneung-ro, Nowon-gu, Seoul, Republic of Korea

E-mail: jwkangims@gmail.com

Hee-young MAENG, Professor,PhD

(Corresponding author)

Seoul National University of Science and Technology,

232, Gongneung-ro, Nowon-gu, Seoul, Republic of Korea

E-mail:maneg@seoultech.ac.kr

\section{Su-In EUN, Deputy Engineer}

II-JinATech 49,

Saneop-ro 382beon-gil, Nam-gu, Ulsan,

Republic of Korea

E-mail: eunsuin@gmail.com 